\title{
Impact of metabolic syndrome on lipid target achievements in the Arabian Gulf: findings from the CEPHEUS study
}

Ibrahim Al-Zakwani 1,2, Wael Al Mahmeed ${ }^{3}$, Abdullah Shehab ${ }^{4}$, Mohamed Arafah', Ali T. Al-Hinai', Omer Al Tamimi ${ }^{7}$, Mahmoud Al Awadhi ${ }^{8}$, Shorook Al Herz ${ }^{9}$, Faisal Al Anazi ${ }^{10}$, Khalid Al Nemer ${ }^{11}$, Othman Metwally ${ }^{12}$, Akram Alkhadra ${ }^{13}$, Mohammed Fakhry ${ }^{13}$, Hossam Elghetany ${ }^{14}$, Abdel Razak Medani ${ }^{15}$, Afzal Hussein Yusufali ${ }^{15}$, Obaid Al Jassim ${ }^{15}$, Omar Al Hallaq ${ }^{16}$, Fahad Omar Ahmed S. Baslaib ${ }^{17}$, Haitham Amin ${ }^{18}$, Khalid Al-Waili ${ }^{19}$, Khamis Al-Hashmi ${ }^{20}$, Raul D. Santos ${ }^{21}$ and Khalid Al-Rasadi ${ }^{19^{*}}$

\begin{abstract}
Background: The aim of this study was to determine the impact of metabolic syndrome (MetS) on lipid target achievements in the Arabian Gulf.

Methods: The centralized pan-middle east survey on the undertreatment of hypercholesterolemia (CEPHEUS) included 4171 high and very high atherosclerotic cardiovascular disease (ASCVD) risk patients from six Arabian Gulf countries. Analyses were performed using univariate statistics.

Results: The overall mean age was $57 \pm 11$ years, $41 \%$ were females and $71 \%$ had MetS. MetS patients were less likely to attain their HDL-C (34 vs. $79 \% ; P<0.001$ ), LDL-C (27 vs. $37 \% ; P<0.001$ ), non HDL-C (35 vs. $55 \%$; $P<0.001$ ) and Apo B (35 vs. $54 \% ; P<0.001)$ compared to those without MetS. Within the MetS cohort, those with very high ASCVD risk were less likely to attain their lipid targets compared to those with high ASCVD risk [HDL-C (32 vs. $41 \%$; $P<0.001)$, LDL-C (24 vs. $43 \% ; P<0.001)$, non HDL-C (32 vs. $51 \% ; P<0.001)$ and Apo B (33 vs. $40 \% ; P=0.001)]$. In those with MetS and very high ASCVD risk status, females were less likely to attain their HDL-C (27 vs. $36 \% ; P<0.001$ ), LDL-C (19 vs. $27 \% ; P<0.001)$ and Apo B (30 vs. $35 \% ; P=0.009$ ) compared to males.
\end{abstract}

Conclusions: MetS was associated with low lipid therapeutic targets. Women and those with very high ASCVD risk were also less likely to attain their lipid targets in the Arabian Gulf.

Keywords: Metabolic syndrome, Cardiovascular diseases, Triglycerides, Obesity, Blood pressure, HDL cholesterol, LDL cholesterol, Arabian Gulf

\section{Background}

The prevalence of metabolic syndrome (MetS) in the general population is $10-15 \%$ higher in the Arabian Gulf than in most developed countries and is more observed in women (32.1-42.7 \%) than men (20.7-37.2 \%) [1]. Similarly, MetS is also highly prevalent (46\%) in patients with acute coronary syndrome (ACS) in the Arabian Gulf $[2$,

\footnotetext{
*Correspondence: k.alrasadi@gmail.com

${ }^{19}$ Department of Biochemistry, Sultan Qaboos University Hospital, P.O Box 38, Al-Khod, 123 Muscat, Oman

Full list of author information is available at the end of the article
}

3]. MetS is associated with increased risk of developing type 2 diabetes mellitus (T2DM), cardiovascular disease (CVD) and mortality $[4,5]$. In the Gulf Registry of Acute Coronary Events (Gulf RACE), which included 8716 consecutive patients hospitalized with ACS in six Arabian Gulf countries, MetS was associated with increased risk for the development of heart failure and recurrent myocardial ischemia without an increase in hospital mortality [2].

The atherogenic dyslipidemia in MetS is characterized by low high-density lipoprotein cholesterol (HDL-C), 
elevated triglyceride (TG) and increased concentration of small, dense low-density lipoprotein (LDL) particles. Lifestyle therapy to improve atherogenic lipid profile should be recommended to all subjects with MetS [6] and if therapeutic lipid targets are not achieved then maximally tolerated statins or combination therapies should be recommended depending on risk stratification [5].

Despite the high prevalence of MetS and dyslipidemia in the Arabian Gulf region, there are currently no published data assessing the gap in the treatment of dyslipidemia in patients with MetS. Hence, the objective of this study was to evaluate the impact of MetS on lipid target achievements among patients with high and very high atherosclerotic cardiovascular disease (ASCVD) risk status in the Centralized Pan-Middle East Survey on the undertreatment of hypercholesterolemia (CEPHEUS) in the Arabian Gulf.

\section{Methods}

The study has been previously described [7]. Briefly, the CEPHEUS study was a multi-centre non-interventional survey of patients on lipid lowering drugs (LLDs) in six Middle Eastern countries (Saudi Arabia, United Arab Emirates, Oman, Qatar, Bahrain, Kuwait). A total of 5457 patients were enrolled in this survey from outpatient clinics by 177 specialists and primary care physicians. The study was conducted between November 22, 2009 and July 7,2010 . The inclusion criteria were: patients $\geq 18$ years of age; taking LLDs for $\geq 3$ months, with no dose change for a minimum of 6 weeks.

A fasting blood sample was taken from each subject for measurement of total cholesterol (TC), HDL-C, lowdensity lipoprotein cholesterol (LDL-C), TG, apolipoprotein A1 (Apo A1), apolipoprotein B (Apo B), glucose and glycated haemoglobin A1c (HbA1c). Blood samples were collected in 3 tubes $(5 \mathrm{ml}$ in a gel tube, $2 \mathrm{ml}$ in a potassium oxalate/sodium fluoride tube and $2 \mathrm{ml}$ in an ethylenediaminetetra-acetic acid (EDTA) tube. The blood samples were shipped by air courier and the tests were performed at the King Faisal specialist Hospital and Research Centre (Riyadh, Saudi Arabia). All the laboratory tests underwent internal and external quality control checks. Criteria for ASCVD risk status was derived from the National Lipid Association (NLA) recommendations for patient-centered management of dyslipidemia part 1-executive summary [8]. High risk group included patients with $\geq 3$ major ASCVD risk factors, diabetes mellitus (type 1 or 2 ) with $0-1$ other major ASCVD risk factor or LDL-C $\geq 190 \mathrm{mg} / \mathrm{dL}(5.02 \mathrm{mmol} / \mathrm{L})$ (severe hypercholesterolemia). Very high risk group included ASCVD and diabetes mellitus with $\geq 2$ other major ASCVD risk factors [8].
As per recent unified definition by the International Diabetes Federation (IDF) and the American Heart Association/National Heart, Lung and Blood Institute (AHA/ NHLBI) using the modified National Cholesterol Education Program-Adult Treatment Panel III (NCEP ATP III) guidelines [9], metabolic syndrome was defined as having 3 or more of the following criteria: (1) increased abdominal obesity (waist circumference of $\geq 94 \mathrm{~cm}$ for men and $\geq 80 \mathrm{~cm}$ for women for Middle Eastern (Mediterranean/European) populations), (2) elevated triglycerides of $\geq 150 \mathrm{mg} / \mathrm{dL}(1.7 \mathrm{mmol} / \mathrm{L})$, (3) reduced HDL-C of $<40 \mathrm{mg} / \mathrm{dL}(1.0 \mathrm{mmol} / \mathrm{L})$ for males and $<50 \mathrm{mg} / \mathrm{dL}$ $(1.3 \mathrm{mmol} / \mathrm{L})$ for females, (4) elevated $\mathrm{BP} \geq 130 \mathrm{mmHg}$ for systolic and/or $\geq 85 \mathrm{mmHg}$ for diastolic, and (5) elevated fasting blood glucose of $\geq 100 \mathrm{mg} / \mathrm{dL}(5.6 \mathrm{mmol} / \mathrm{L})$.

Therapeutic lipoprotein targets for the high ASCVD risk patients were $\mathrm{LDL}-\mathrm{C}<2.6 \mathrm{mmol} / \mathrm{L}(100 \mathrm{mg} / \mathrm{dL})$ and LDL-C $<1.8 \mathrm{mmol} / \mathrm{L}(70 \mathrm{mg} / \mathrm{dL}$ ) for those with high and very high ASCVD risk status, respectively [8]. Blood pressure (BP) goals were adapted from the new Eighth Joint National Committee (JNC-8) 2014 Hypertension Guideline Management Algorithm. BP goals for those without diabetes mellitus (DM) and $\geq 60$ years and those $<60$ years were $<150 / 90 \mathrm{mmHg}$ and $<140 / 90 \mathrm{mmHg}$, respectively. For those with DM irrespective of age, the BP goal was $<140 / 90 \mathrm{mmHg}$ [10].

\section{Statistical analysis}

Descriptive statistics were used to describe the data. For categorical variables, frequencies and percentages were reported. Differences between groups were analyzed using Pearson's $X^{2}$ tests (or Fisher's exact tests for cells $<5)$. For continuous variables, mean and standard deviation were used to summarize the data. Analyses were performed using Student's $t$ test. An a priori two-tailed level of significance was set at 0.05 . Statistical analyses were conducted using STATA version 13.1 (STATA Corporation, College Station, TX, USA).

\section{Ethics approval}

This study complied with the declaration of Helsinki and had approval from the internal review bodies/ethics committees of each participating institution in each of the Arabian Gulf countries (CEPHEUS; Study Code: SRPCB-CRE-2006/01). Informed written consent was also obtained from all patients enrolled in the study.

\section{Results}

In total, 5457 patients participated in the survey. However, those that had missing laboratory data, underage ( $<18$ years), missing risk level data as well as those with low and moderate risk were not included in this study. 
Therefore, the final study sample comprised of 4171 high and very high ASCVD risk patients.

Table 1 outlines the demographics and clinical characteristics of the cohort. The overall mean age of the cohort was $57 \pm 11$ years with $41 \%(\mathrm{n}=1711)$ females and $77 \%$ $(\mathrm{n}=3215)$ Arab Gulf citizens. The average body mass index (BMI) was $31 \pm 7 \mathrm{~kg} / \mathrm{m}^{2}$. The proportion of patients with coronary heart disease (CHD), diabetes mellitus and hypertension were $36 \%(\mathrm{n}=1511), 77 \%(\mathrm{n}=3205)$ and $70 \%(\mathrm{n}=2906)$, respectively. Most of the patients (78\%; $\mathrm{n}=3261)$ had very high ASCVD risk status. Majority $(94 \% ; n=3928)$ were on statin monotherapy. Patients on statin combination and other dyslipidemic therapy were $4.8 \%(\mathrm{n}=202)$ and $1.0 \%(\mathrm{n}=41)$, respectively.

MetS patients were more likely to be female (46 vs. $30 \% ; P<0.001)$, associated with higher waist circumference (106 vs. $99 \mathrm{~cm} ; P<0.001)$ and BMI (32 vs. $29 \mathrm{~kg} / \mathrm{m}^{2}$; $P<0.001$ ), hypertensive (73 vs. $62 \% ; P<0.001$ ), diabetic (83 vs. $63 \% ; P<0.001$ ) and very high ASCVD risk status (81 vs. $73 \% ; P<0.001$ ). MetS patients were also less likely to attain HDL-C (34 vs. $79 \% ; P<0.001$ ), LDL-C (27 vs. $37 \%$; $P<0.001$ ), Apo B (35 vs. $54 \% ; P<0.001$ ) and non HDL-C ( 35 vs. $55 \%$; $P<0.001$ ) lipid targets.

Figure 1 shows that the number of patients with 1,2 , 3, 4 and 5 MetS risk factors were $7.0 \%(\mathrm{n}=291), 21 \%$ $(\mathrm{n}=888), 32 \%(\mathrm{n}=1339), 26 \%(\mathrm{n}=1087)$ and $13 \%$ $(n=522)$, respectively. Figure 2 outlines the lipid target achievements (HDL-C, LDL-C, non HDL-C and Apo B) in metabolic syndrome patients stratified by ASCVD risk status. MetS patients with very high ASCVD risk status were less likely to attain HDL-C ( 32 vs. $41 \%$; $P<0.001$ ), LDL-C ( 24 vs. $43 \%$; $P<0.001)$, non HDL-C (32 vs. $51 \%$; $P<0.001$ ) and Apo B (33 vs. $40 \% ; P=0.001$ ) lipid targets when compared to those with high ASCVD risk status.

In MetS patients with very high ASCVD risk status (Fig. 3), females were less likely to attain HDL-C (27 vs. $36 \% ; P<0.001)$, LDL-C (19 vs. $27 \% ; P<0.001)$ and Apo B (30 vs. $35 \%$; $P=0.009$ ) lipid targets when compared to males. However, there were no significant differences in lipid target achievements between genders in MetS patients with high ASCDV risk status (Fig. 4).

\section{Discussion}

To our best knowledge this the first study to assess the lipid attainment goals in patients with MetS in the Arabian Gulf. The prevalence of MetS was $71 \%$ in patients on LLDs in the Arabian Gulf. MetS was more prevalent in the Gulf citizens, females and patients with very high ASCVD risk status. Patients with MetS were significantly less likely to attain their LDL-C (27 vs. $37 \%$; $P<0.001)$, non HDL-C ( 35 vs. $55 \% ; P<0.001$ ) and apo B ( 35 vs. $54 \% ; P<0.001$ ) targets compared to patients without MetS.
MetS is defined as a cluster of cardiovascular risk factors including central obesity, raised serum TG, reduced HDL-C, glucose intolerance, and hypertension [5, 9]. Additional abnormalities like the pro-inflammatory and pro-thrombotic factors are considered part of the constellation of risk factors in MetS [5, 11], that were not measured in the current study. There are several guideline definitions of MetS [12], The calculation of the MetS prevalence in the current study was based on the harmonized definition developed by the a joint statement of the International Diabetes Federation (IDF) Task Force on Epidemiology and Prevention, National Heart, Lung and Blood Institute/American Heart Association (NHLBVAHA), the World Heart Federation, the International Atherosclerosis Society, and the International Association for the Study of Obesity [9].

Insulin resistance plays a major role in lipid derangement in patients with MetS, which is characterized by both quantitative dyslipidemia (high TG and low HDLC) and qualitative dyslipidemia (small, dense, apo B-100rich LDL). These phenotypes of atherogenic dyslipidemia in the presence or absence of increased levels of LDL-C is the most frequent dyslipidemia observed in patients with MetS and are strongly associated with atherosclerosis and premature coronary artery disease (CAD) [12-18]. In insulin resistance, there is an increase in free fatty acids (FFAs) flux to the liver that stimulate the synthesis of very low density lipoprotein (VLDL) particles and results in high TG levels and Apo B particles in plasma. Insulin resistance can also impair the lipolysis of VLDL particles that leads to an accumulation of triglyceride-rich remnant lipoproteins (VLDL-remnants) and subsequent transfer of cholesterol esters in exchange for triglycerides from the HDL particles to the triglyceride-rich remnant through the action of cholesterol ester transfer protein (CETP). This will results in smaller HDL particles and low levels of HDL-C [19-23]. Moreover, insulin resistance is associated with an increase in C-reactive protein (CRP), a marker of inflammation which has been shown to increase linearly with the number of metabolic syndrome components present [24], associated with a higher risk of developing diabetes [25, 26] and CAD [27].

MetS identifies people at a higher risk of CVD and diabetes than the general population. MetS is a five-fold increased risk of diabetes, a two-fold increase in cardiovascular outcomes and 1.5-fold increase in all-cause mortality according to the recent meta-analysis $[4,16$, 28]. In our study, $32 \%$ of the MetS cohort carried three of the major cardiovascular risk factors. Moreover, MetS was observed in $81 \%$ of patients with very high ASCVD compared to $20 \%$ of high ASCVD risk status. Therefore, this highlights the high cardiovascular risk profile of our 
Table 1 Demographic and clinical characteristics stratified by metabolic syndrome

\begin{tabular}{|c|c|c|c|c|}
\hline Characteristic, $n$ (\%) unless specified otherwise & All $(N=4171)$ & No MetS $(n=1223) 29 \%$ & Mets $(n=2948) 71 \%$ & Pvalue \\
\hline Gulf citizen & $3215(77 \%)$ & $874(71 \%)$ & $2341(79 \%)$ & $<0.001$ \\
\hline Female gender & $1711(41 \%)$ & $366(30 \%)$ & $1345(46 \%)$ & $<0.001$ \\
\hline Age, mean $\pm S D$, years & $57 \pm 11$ & $57 \pm 12$ & $57 \pm 11$ & 0.620 \\
\hline Weight, mean $\pm S D$, kg & $82 \pm 17$ & $78 \pm 17$ & $84 \pm 17$ & $<0.001$ \\
\hline Waist circumference, mean $\pm \mathrm{SD}, \mathrm{cm}$ & $104 \pm 14$ & $99 \pm 14$ & $106 \pm 13$ & $<0.001$ \\
\hline $\mathrm{BMI}$, mean $\pm \mathrm{SD}, \mathrm{kg} / \mathrm{m}^{2}$ & $31 \pm 7$ & $29 \pm 6$ & $32 \pm 7$ & $<0.001$ \\
\hline $\mathrm{BMI}>30 \mathrm{~kg} / \mathrm{m}^{2}$ & $2219(53 \%)$ & $484(40 \%)$ & $1735(59 \%)$ & $<0.001$ \\
\hline Current smoker & $517(12 \%)$ & $168(14 \%)$ & $349(12 \%)$ & 0.090 \\
\hline Hypertension & $2906(70 \%)$ & 750 (61 \%) & $2156(73 \%)$ & $<0.001$ \\
\hline Coronary heart disease & 1511 (36\%) & $554(45 \%)$ & $957(32 \%)$ & $<0.001$ \\
\hline Peripheral vascular disease & $142(3.4 \%)$ & $52(4.3 \%)$ & $90(3.1 \%)$ & 0.052 \\
\hline Cerebrovascular disease & $183(4.4 \%)$ & $53(4.3 \%)$ & $130(4.4 \%)$ & 0.913 \\
\hline Diabetes mellitus & 3205 (77\%) & 768 (63\%) & $2437(83 \%)$ & $<0.001$ \\
\hline $\mathrm{HbA} 1 \mathrm{c}$, mean $\pm \mathrm{SD}, \%$ & $8.62 \pm 3.79$ & $7.84 \pm 2.61$ & $8.88 \pm 4.06$ & $<0.001$ \\
\hline $\mathrm{HbA} 1 \mathrm{c}<7 \%$ & $820(26 \%)$ & $320(42 \%)$ & $500(21 \%)$ & $<0.001$ \\
\hline \multicolumn{5}{|l|}{ ASCVD risk status } \\
\hline High risk & $910(22 \%)$ & $335(27 \%)$ & $575(20 \%)$ & $<0.001$ \\
\hline Very high risk & $3261(78 \%)$ & $888(73 \%)$ & $2373(81 \%)$ & $<0.001$ \\
\hline \multicolumn{5}{|l|}{ Dyslipidaemic therapy } \\
\hline Statin monotherapy & 3928 (94 \%) & $1146(94 \%)$ & $2782(94 \%)$ & 0.218 \\
\hline Statin combination & $202(4.8 \%)$ & $67(5.5 \%)$ & $135(4.6 \%)$ & 0.486 \\
\hline Others & $41(1.0 \%)$ & $10(0.8 \%)$ & $31(1.1 \%)$ & 0.404 \\
\hline \multicolumn{5}{|c|}{ Lipid levels on treatment, mean $\pm S D, m m o l / L$, unless specified otherwise } \\
\hline TC & $4.31 \pm 1.11$ & $4.15 \pm 1.08$ & $4.38 \pm 1.12$ & $<0.001$ \\
\hline LDL-C & $2.54 \pm 0.94$ & $2.43 \pm 0.95$ & $2.58 \pm 0.93$ & $<0.001$ \\
\hline HDL-C & $1.15 \pm 0.31$ & $1.30 \pm 0.32$ & $1.10 \pm 0.28$ & $<0.001$ \\
\hline Apo B, g/L & $0.92 \pm 0.27$ & $0.84 \pm 0.26$ & $0.95 \pm 0.27$ & $<0.001$ \\
\hline Non-HDL-C & $3.16 \pm 1.09$ & $2.85 \pm 1.01$ & $3.28 \pm 1.09$ & $<0.001$ \\
\hline TG & $1.75 \pm 1.27$ & $1.19 \pm 0.46$ & $1.98 \pm 1.42$ & $<0.001$ \\
\hline \multicolumn{5}{|l|}{ Lipid goal attainments, $n$ (\%) } \\
\hline HDL-C goal & $1952(47 \%)$ & $963(79 \%)$ & $989(34 \%)$ & $<0.001$ \\
\hline LDL-C goal & $1258(30 \%)$ & $449(37 \%)$ & $809(27 \%)$ & $<0.001$ \\
\hline Apo B goal & $1676(40 \%)$ & $658(54 \%)$ & $1018(35 \%)$ & $<0.001$ \\
\hline Non-HDL-C goal & $1715(41 \%)$ & $673(55 \%)$ & $1042(35 \%)$ & $<0.001$ \\
\hline \multicolumn{5}{|l|}{ Blood pressure (BP), mean \pm SD unless specified otherwise } \\
\hline Systolic BP, mmHg & $133 \pm 19$ & $125 \pm 17$ & $136 \pm 18$ & $<0.001$ \\
\hline Diastolic BP, mmHg & $79 \pm 10$ & $75 \pm 10$ & $80 \pm 10$ & $<0.001$ \\
\hline BP control, n (\%) & $2497(60 \%)$ & $957(78 \%)$ & $1540(52 \%)$ & $<0.001$ \\
\hline
\end{tabular}

As per recent unified definition by the International Diabetes Federation (IDF) and the American Heart Association/National Heart, Lung and Blood Institute (AHA/ NHLBI) using the modified National Cholesterol Education Program-Adult Treatment Panel III (NCEP ATP III) guidelines, MetS was defined as having 3 or more of the following criteria: (1) increased abdominal obesity (waist circumference of $\geq 94 \mathrm{~cm}$ for men and $\geq 80 \mathrm{~cm}$ for women for Middle Eastern (Mediterranean/European) populations), (2) elevated triglycerides of $\geq 150 \mathrm{mg} / \mathrm{dL}$ ( $1.7 \mathrm{mmol} / \mathrm{L}$ ), (3) reduced HDL-C of $<40 \mathrm{mg} / \mathrm{dL}$ ( $1.04 \mathrm{mmol} / \mathrm{L}$ ) for males and $<50 \mathrm{mg} / \mathrm{dL}$ ( $1.3 \mathrm{mmol} / \mathrm{L}$ ) for females, (4) elevated BP $\geq 130 \mathrm{mmHg}$ for systolic and/or $\geq 85 \mathrm{mmHg}$ for diastolic, and (5) elevated fasting blood glucose of $\geq 100 \mathrm{mg} / \mathrm{dL}$ (5.6 mmol/L)

Criteria for ASCVD risk status was adapted from the National Lipid Association criteria for atherosclerotic cardiovascular disease. High risk group included patients with $\geq 3$ major ASCVD risk factors, diabetes mellitus (type 1 or 2) with 0/1 major ASCVD risk factor and LDL-C $\geq 190 \mathrm{mg} / \mathrm{dL}(5.02 \mathrm{mmol} / \mathrm{L}$ ) (severe hypercholesterolemia). Very high risk group included ASCVD (CHD, PAD, CVD), diabetes mellitus with $\geq 2$ other major ASCVD risk factors

Despite the lack of a recommended HDL-C goal by guidelines, satisfactory HDL-C was defined as $<40 \mathrm{mg} / \mathrm{dL}(1.04 \mathrm{mmol} / \mathrm{L})$ for males or $<50 \mathrm{mg} / \mathrm{dL}(1.3 \mathrm{mmol} / \mathrm{L}) \mathrm{for}$ females. Therapeutic lipoprotein targets for the high risk patients were $\mathrm{LDL}-\mathrm{C}<2.6 \mathrm{mmol} / \mathrm{L}$, apo $\mathrm{B}<0.90 \mathrm{~g} / \mathrm{L}$ and non-HDL- $\mathrm{C}<3.3 \mathrm{mmol} / \mathrm{L}$. For the highest risk group therapeutic lipoprotein targets were $\mathrm{LDL}-\mathrm{C}<1.8 \mathrm{mmol} / \mathrm{L}$, apo $\mathrm{B}<0.80 \mathrm{~g} / \mathrm{L}$ and non- $\mathrm{HDL}-\mathrm{C}<2.6 \mathrm{mmol} / \mathrm{L}$

BP goals were adapted from the new JNC-8 2014 Hypertension Guideline Management Algorithm. BP goals for those without diabetes mellitus (DM) and $\geq 60$ years and those $<60$ years were $<150 / 90 \mathrm{mmHg}$ and $<140 / 90 \mathrm{mmHg}$, respectively. For those with DM irrespective of age, the BP goal was $<140 / 90 \mathrm{mmHg}$

MetS metabolic syndrome, $S D$ standard deviation, $B M I$ body mass index, $C H D$ coronary heart disease, $P A D$ peripheral arterial disease, CVD cardiovascular disease, $A S C V D$ atherosclerotic cardiovascular disease, TC total cholesterol, $L D L-C$ low-density lipoprotein cholesterol, $H D L$-C high-density lipoprotein cholesterol, $A p o B$ apolipoprotein B, TG triglyceride 


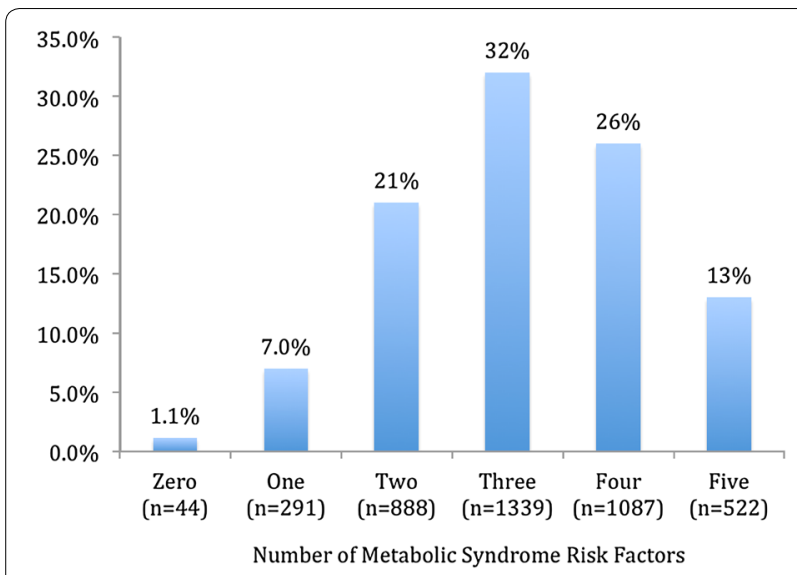

Fig. 1 Number of metabolic syndrome (MetS) risk factors (increased abdominal obesity, elevated triglycerides, reduced HDL-C, elevated blood pressure, and elevated blood glucose) in atherosclerotic cardiovascular disease (ASCVD) risk patients $(N=4171)$. As per recent unified definition by the International Diabetes Federation (IDF) and the American Heart Association/National Heart, Lung and Blood Institute (AHA/NHLBI) using the modified National Cholesterol Education Program-Adult Treatment Panel III (NCEP ATP III) guidelines, MetS was defined as having three or more of the following criteria: (1) increased abdominal obesity (waist circumference of $\geq 94 \mathrm{~cm}$ for men and $\geq 80 \mathrm{~cm}$ for women for Middle Eastern (Mediterranean/ European) populations), (2) elevated triglycerides of $\geq 150 \mathrm{mg} /$ $\mathrm{dL}$ (1.7 mmol/L), (3) reduced HDL-C of $<40 \mathrm{mg} / \mathrm{dL}$ (1.04 mmol/L) for males and $<50 \mathrm{mg} / \mathrm{dL}$ (1.3 mmol/L) for females, (4) elevated BP $\geq 130 \mathrm{mmHg}$ for systolic and/or $\geq 85 \mathrm{mmHg}$ for diastolic, and (5) elevated fasting blood glucose of $\geq 100 \mathrm{mg} / \mathrm{dL}$ ( $5.6 \mathrm{mmol} / \mathrm{L})$. Criteria for ASCVD risk status was adapted from the National Lipid Association criteria for atherosclerotic cardiovascular disease. High risk group included patients with $\geq 3$ major ASCVD risk factors, diabetes mellitus (type 1 or 2) with 0/1 major ASCVD risk factor and LDL-C $\geq 190 \mathrm{mg} /$ $\mathrm{dL}(5.02 \mathrm{mmol} / \mathrm{L})$ (severe hypercholesterolemia). Very high risk group included ASCVD (CHD, PAD, CVD), diabetes mellitus with $\geq 2$ other major ASCVD risk factors

patients and the need for more intensive risk factors stratification and treatment in this population.

The management of MetS should focus on reducing both short and long term risk of developing subsequent cardiovascular events. The treatment should focus on optimal controlling of the various components of MetS. Life style modifications through weight loss, diet and exercise [6] should be the first line intervention in patients with MetS. However, in patients with high, very high ASCVD risk and in patients who fail life style intervention pharmacological therapies should be considered to control atherogenic dyslipidemia [8, 29, 30], diabetes [31], hypertension [10] and current guidelines for their management should be followed. For the treatment of atherogenic dyslipidemia, statins are recommended as the first line therapy. Although currently there are no clinical trials addressing the cardiovascular outcomes

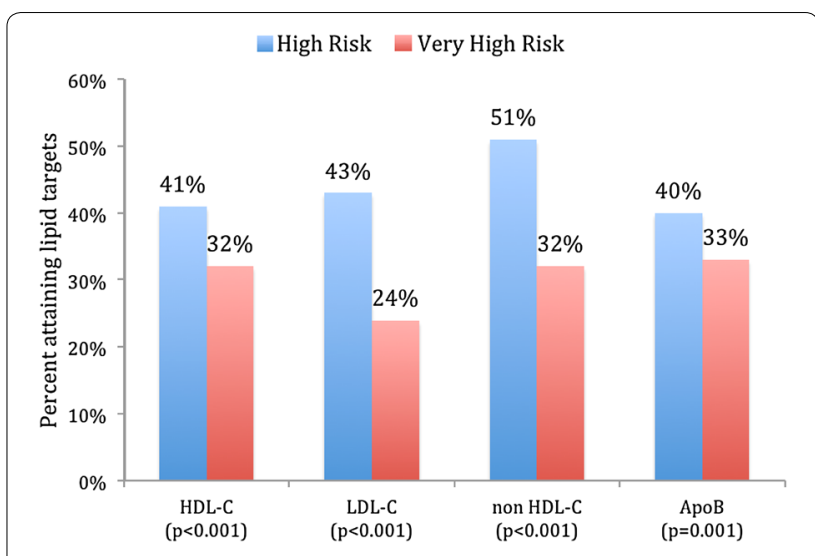

Fig. 2 Lipid target achievements (HDL-C, LDL-C, non HDL-C and Apo B) in metabolic syndrome patients stratified by atherosclerotic cardiovascular disease (ASCVD) risk status ( $N=2948)$. HDL-C high-density lipoprotein cholesterol, LDL-C low-density lipoprotein cholesterol, Apo $B$ apolipoprotein B. As per recent unified definition by the International Diabetes Federation (IDF) and the American Heart Association/National Heart, Lung and Blood Institute (AHA/NHLBI) using the modified National Cholesterol Education Program-Adult Treatment Panel III (NCEP ATP III) guidelines, MetS was defined as having three or more of the following criteria: (1) increased abdominal obesity (waist circumference of $\geq 94 \mathrm{~cm}$ for men and $\geq 80 \mathrm{~cm}$ for women for middle eastern (Mediterranean/European) populations), (2) elevated triglycerides of $\geq 150 \mathrm{mg} / \mathrm{dL}(1.7 \mathrm{mmol} / \mathrm{L})$, (3) reduced $\mathrm{HDL}-\mathrm{C}$ of $<40 \mathrm{mg} / \mathrm{dL}(1.0 \mathrm{mmol} / \mathrm{L})$ for males and $<50 \mathrm{mg} / \mathrm{dL}(1.3 \mathrm{mmol} / \mathrm{L})$ for females, (4) elevated BP $\geq 130 \mathrm{mmHg}$ for systolic and/or $\geq 85 \mathrm{mmHg}$ for diastolic, and (5) elevated fasting blood glucose of $\geq 100 \mathrm{mg}$ / $\mathrm{dL}$ (5.6 mmol/L). Criteria for ASCVD risk status was adapted from the National Lipid Association criteria for atherosclerotic cardiovascular disease. High risk group included patients with $\geq 3$ major ASCVD risk factors, diabetes mellitus (type 1 or 2) with 0-1 major ASCVD risk factors, LDL-C $\geq 190 \mathrm{mg} / \mathrm{dL}$ (severe hypercholesterolemia). Very high risk group included ASCVD (CHD, PAD, CVD), diabetes mellitus with $\geq 2$ other major ASCVD risk factors. Despite the lack of a recommended HDL-C goal by guidelines, satisfactory HDL-C was defined as $<40 \mathrm{mg} /$ $\mathrm{dL}(1.03 \mathrm{mmol} / \mathrm{L})$ for males or $<50 \mathrm{mg} / \mathrm{dL}$ (1.29 mmol/L) for females. Therapeutic lipoprotein targets for the highest risk group were $\mathrm{LDL}-\mathrm{C}<1.8 \mathrm{mmol} / \mathrm{L}$, apo $\mathrm{B}<0.80 \mathrm{~g} / \mathrm{L}$ and non-HDL-C $<2.6 \mathrm{mmol} / \mathrm{L}$

of LLDs on patients with the MetS, nevertheless, in the subgroup of patients with MetS, clinical trials showed benefits from LLDs particularly statins on reducing cardiovascular events that is considered similar or greater, compared with overall study populations [32-35].

Moreover, in the Treating to New Target study (TNT) trial, in the subgroup of patients with MetS, CAD and no diabetes there was a significant additional benefit on cardiovascular events when high dose atorvastatin of $80 \mathrm{mg}$ was used compared to the low atorvastatin dose of $10 \mathrm{mg}$ [32]. The use of combination therapy to optimize other lipid targets beyond LDL-C like non HDL-C, Apo $\mathrm{B}$, TG and HDL-C may be considered in treating atherogenic dyslipidemia in MetS. Non HDL-C is considered to be a better predictor of $\mathrm{CV}$ risk and therapeutic target 


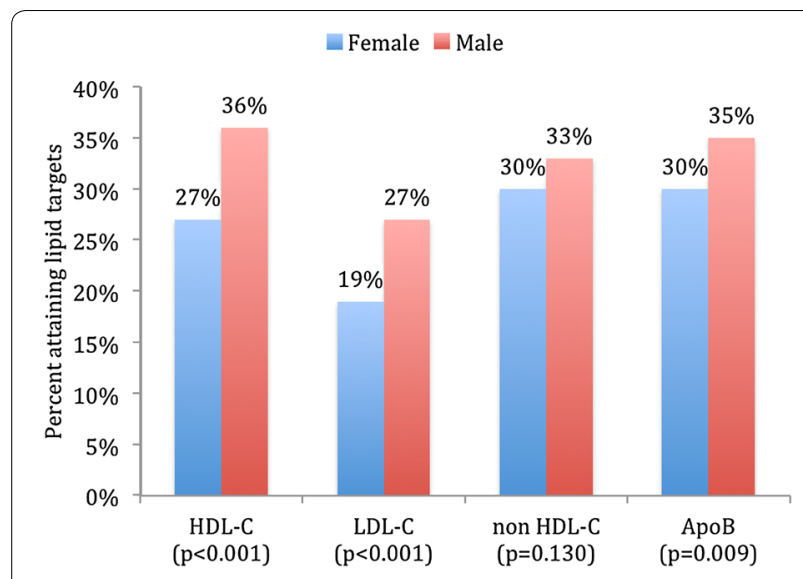

Fig. 3 Lipid target achievements (HDL-C, LDL-C, non HDL-C and Apo $B)$ in patients with metabolic syndrome and very high atherosclerotic cardiovascular disease (ASCVD) risk status stratified by gender $(N=2373)$. HDL-C high-density lipoprotein cholesterol, LDL-C lowdensity lipoprotein cholesterol, Apo B, apolipoprotein B. As per recent unified definition by the International Diabetes Federation (IDF) and the American Heart Association/National Heart, Lung and Blood Institute (AHA/NHLBI) using the modified National Cholesterol Education Program-Adult Treatment Panel III (NCEP ATP III) guidelines, MetS was defined as having 3 or more of the following criteria: (1) increased abdominal obesity (waist circumference of $\geq 94 \mathrm{~cm}$ for men and $\geq 80 \mathrm{~cm}$ for women for Middle Eastern (Mediterranean/European) populations), (2) elevated triglycerides of $\geq 150 \mathrm{mg} / \mathrm{dL}(1.7 \mathrm{mmol} / \mathrm{L})$, (3) reduced HDL-C of $<40 \mathrm{mg} / \mathrm{dL}$ ( $1.0 \mathrm{mmol} / \mathrm{L})$ for males and $<50 \mathrm{mg} /$ $\mathrm{dL}(1.3 \mathrm{mmol} / \mathrm{L}$ ) for females, (4) elevated BP $\geq 130 \mathrm{mmHg}$ for systolic and/or $\geq 85 \mathrm{mmHg}$ for diastolic, and (5) elevated fasting blood glucose of $\geq 100 \mathrm{mg} / \mathrm{dL}$ (5.6 mmol/L). Criteria for ASCVD risk status was adapted from the National Lipid Association criteria for atherosclerotic cardiovascular disease. High risk group included patients with $\geq 3$ major ASCVD risk factors, diabetes mellitus (type 1 or 2 ) with 0-1 major ASCVD risk factors, $\mathrm{LDL}-\mathrm{C} \geq 190 \mathrm{mg} / \mathrm{dL}$ (severe hypercholesterolemia). Very high risk group included ASCVD (CHD, PAD, CVD), diabetes mellitus with $\geq 2$ other major ASCVD risk factors. Despite the lack of a recommended HDL-C goal by guidelines, satisfactory $\mathrm{HDL}-\mathrm{C}$ was defined as $<40 \mathrm{mg} / \mathrm{dL}$ ( $1.03 \mathrm{mmol} / \mathrm{L}$ ) for males or $<50 \mathrm{mg} / \mathrm{dL}$ $(1.29 \mathrm{mmol} / \mathrm{L})$ for females. Therapeutic lipoprotein targets for the highest risk group were $\mathrm{LDL}-\mathrm{C}<1.8 \mathrm{mmol} / \mathrm{L}$, apo $\mathrm{B}<0.80 \mathrm{~g} / \mathrm{L}$ and non-HDL-C $<2.6 \mathrm{mmol} / \mathrm{L}$

than LDL-C, particularly in patients with diabetes and MetS, and therefore the NLA in their recent guideline, have placed non HDL-C ahead of LDL-C as a therapeutic target [8]. Apart from adding ezetimibe to statins for combination therapy [36], other combination therapies like fibrates and niacin [37] have failed to show additional benefits in reducing cardiovascular events. Nonetheless, adding fibrates particularly fenofibrate to statins, have proven to be safe and effective in reducing cardiovascular events in subgroup of patients with obesity, high TG and low HDL-C [38, 39] and therefore, should be considered to treat high risk patients with atherogenic dyslipidemia when high dose statins failed to achieve the lipid therapeutic targets.

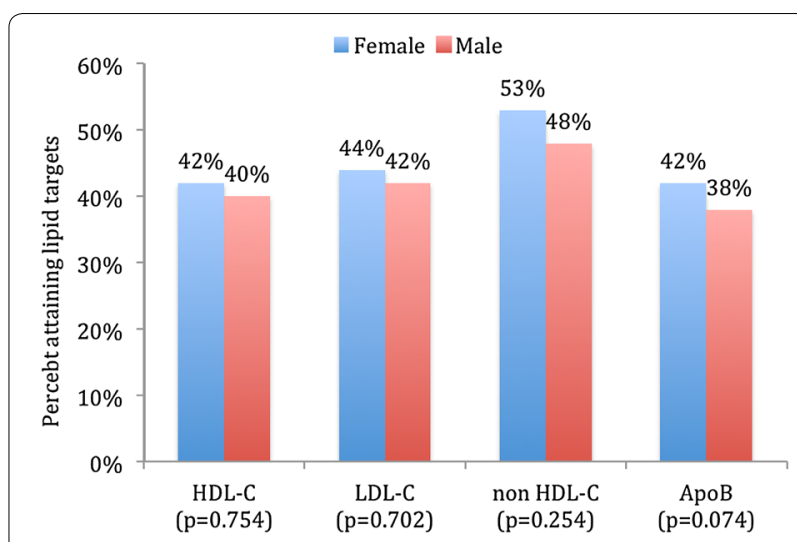

Fig. 4 Lipid target achievements (HDL-C, LDL-C, non HDL-C and Apo $\mathrm{B})$ in patients with metabolic syndrome and high atherosclerotic cardiovascular disease (ASCVD) risk status stratified by gender $(N=575)$. $H D L-C$ high-density lipoprotein cholesterol, LDL-C low-density lipoprotein cholesterol, Apo B apolipoprotein B. As per recent unified definition by the International Diabetes Federation (IDF) and the American Heart Association/National Heart, Lung and Blood Institute (AHA/NHLBI) using the modified National Cholesterol Education Program-Adult Treatment Panel III (NCEP ATP III) guidelines, MetS was defined as having 3 or more of the following criteria: (1) increased abdominal obesity (waist circumference of $\geq 94 \mathrm{~cm}$ for men and $\geq 80 \mathrm{~cm}$ for women for Middle Eastern Mediterranean/European) populations), (2) elevated triglycerides of $\geq 150 \mathrm{mg} / \mathrm{dL}(1.7 \mathrm{mmol} / \mathrm{L})$, (3) reduced $\mathrm{HDL}-\mathrm{C}$ of $<40 \mathrm{mg} / \mathrm{dL}(1.0 \mathrm{mmol} / \mathrm{L})$ for males and $<50 \mathrm{mg} /$ $\mathrm{dL}(1.3 \mathrm{mmol} / \mathrm{L})$ for females, (4) elevated $\mathrm{BP} \geq 130 \mathrm{mmHg}$ for systolic and/or $\geq 85 \mathrm{mmHg}$ for diastolic, and (5) elevated fasting blood glucose of $\geq 100 \mathrm{mg} / \mathrm{dL}$ ( $5.6 \mathrm{mmol} / \mathrm{L})$. Criteria for ASCVD risk status was adapted from the National Lipid Association criteria for atherosclerotic cardiovascular disease. High risk group included patients with $\geq 3$ major ASCVD risk factors, diabetes mellitus (type 1 or 2) with 0-1 major ASCVD risk factors, LDL-C $\geq 190 \mathrm{mg} / \mathrm{dL}$ (severe hypercholesterolemia). Very high risk group included ASCVD (CHD, PAD, CVD), diabetes mellitus with $\geq 2$ other major ASCVD risk factors. Despite the lack of a recommended $\mathrm{HDL}-\mathrm{C}$ goal by guidelines, satisfactory $\mathrm{HDL}-\mathrm{C}$ was defined as $<40 \mathrm{mg} / \mathrm{dL}(1.03 \mathrm{mmol} / \mathrm{L})$ for males or $<50 \mathrm{mg} / \mathrm{dL}$ $(1.29 \mathrm{mmo} / \mathrm{L})$ for females. Therapeutic lipoprotein targets for the high risk patients were $L D L-C<2.6 \mathrm{mmol} / \mathrm{L}$, apo $B<0.90 \mathrm{~g} / \mathrm{L}$ and non-HDL$\mathrm{C}<3.3 \mathrm{mmol} / \mathrm{L}$

In our study MetS patients with very high ASCVD risk status were less likely to attain LDL-C ( 24 vs. $43 \%$; $P<0.001)$ and non HDL-C (32 vs. $51 \%$; $P<0.001)$ lipid targets when compared with those with high ASCVD risk status. Compared to the Dyslipidemia International Study of China (DYSIS-China), which was an observational study of 25,697 patients, in which $37 \%$ had CAD, $57 \%$ had diabetes and over one-third had MetS. LDL-C goal was achieved in $47 \%$ of patients with MetS compared to $69 \%$ in those without the MetS $(P<0.001)$. Non HDL-C goals were achieved in $51 \%$ of patients with MetS compared to $72 \%$ in those without the MetS $(P<0.001)$. Among very high-risk individuals, only $26 \%$ achieved their LDL-C goal and $42 \%$ attained their non HDL-C goal [40]. Similar to the DYSIS-China study, the current 
study showed that the majority of MetS patients were on statin therapy (94\%), the use of other non-statin (1.1\%) or combination therapies (4.6\%) were low [7]. Therefore, the recommendation from both studies is to increase the awareness of both patients and clinicians regarding the atherogenic dyslipidemia and increased ASCVD risk associated with the MetS. In order to improve therapeutic lipid goals attainment and reduce ASCVD risk in MetS, effective strategies need to be developed and implemented and should primarily focused on life style modifications and to use more intensive LLDs and combination therapies in patients with very-high risk ASCVD risk status.

In a systematic review conducted by Mabry and colleagues, the reported prevalence of the MetS in the general population in the Arabian Gulf is $10-15 \%$ higher than in most developed countries and it is higher in women (32.1-42.7 \%) than men (20.7-37.2 \%) [1]. There was no report concerning statin use and the attainment of lipid targets in this systematic review [1]. We observed similar higher prevalence of MetS in women than men (46 vs. $30 \%$; $P<0.001$ ). Moreover; in our study females with MetS and very high ASCVD risk status were less likely to attain lipid targets when compared to males. The gap in lipid goals between men and women in our study may be explained by the high prevalence of T2DM and MetS in women compared to men. In addition, these findings may be associated with other factors like baseline lipid levels, socioeconomic status, marital status and the dosage of statin [41-43]. The prevalence of MetS in our study $(71 \%)$ was higher than that seen in the Gulf RACE study (46\%), in patients with ACS in the Arabian Gulf. In this study they observed higher statin usage among patients with MetS compared to patients with no MetS (83 vs. 79 \%) but there was no report concerning the attainment of lipid targets $[2,3]$. The difference in the prevalence of metabolic syndrome between these studies can be explained by factors like the type of the population understudy, the number of cardiovascular co-morbidities and other associated risk factors and the difference in the criteria used to define MetS.

Our findings provide a useful overview of current lipid management and treatment outcomes in patients with MetS in the Middle East. However, they study is not without limitations; it is an observational cross-sectional trial that did not assess long-term outcomes. A prospective follow-up study is required to evaluate medical treatment and attainment in relation to mortality in patients treated with LLDs. The population studied is relatively small and considerable variability in practice patterns across the Arabian Gulf exists, and probably even among study sites, and therefore caution should be exercised when extrapolating the results to the general population. In addition, the population included only patients who were already on LLDs. It was not clear what proportion of eligible patients with appropriate risk factors were offered LLDs in different countries. Such information would be important to evaluate the overall burden of the disease among untreated patients in various countries.

\section{Conclusion}

This study has demonstrated that MetS is highly prevalent and is associated with low attainment of lipid therapeutic targets in the Arabian Gulf. Furthermore, women and those with very high ASCVD risk were also less likely to attain their lipid targets. In order to improve therapeutic lipid goal attainment and reduce ASCVD risk in MetS in the Arabian Gulf region, effective strategies need to be developed and implemented and should primarily be focused on life style modifications and more intensive LLDs and combination therapies in patients with high risk ASCVD risk status.

\section{Abbreviations}

CEPHEUS: centralized pan-middle east survey on the undertreatment of hypercholesterolemia; MetS: metabolic syndrome; ASCVD: atherosclerotic cardiovascular disease; HDL-C: high-density lipoprotein cholesterol; LDL-C: low-density lipoprotein cholesterol; Apo B: apolipoprotein B; ACS: acute coronary syndrome; Gulf RACE: Gulf Registry of Acute Coronary Events; TG: triglyceride; LLD: lipid lowering drugs; TC: total cholesterol; Apo A1: apolipoprotein A1; HbA1c: glycated hemoglobin; EDTA: ethylenediaminetetra-acetic acid; NLA: National Lipid Association; IDF: International Diabetes Federation; AHA/ NHLBI: American Heart Association/National Heart, Lung and Blood Institute; NCEP ATP III: National Cholesterol Education Program-Adult Treatment Panel III; JNC-8: Eighth Joint National Committee; BP: blood pressure; DM: diabetes mellitus; BMI: body mass index; CHD: coronary heart disease; CAD: coronary artery disease; FFAs: free fatty acids; VLDL: very low density lipoprotein; CETP: cholesterol ester transfer protein; CRP: C-reactive protein; TNT: treating to new target study

\section{Authors' contributions}

All authors participated in the design and of the study and writing of the manuscript. IA performed statistical analyses. All authors read and approved the final manuscript.

\footnotetext{
Author details

${ }^{1}$ Department of Pharmacology \& Clinical Pharmacy, College of Medicine \& Health Sciences, Sultan Qaboos University, Muscat, Oman. ${ }^{2}$ Gulf Health Research, Muscat, Oman. ${ }^{3}$ Heart and Vascular Institute-Cleveland Clinic, Abu Dhabi, United Arab Emirates. ${ }^{4}$ UAE University, Alain, United Arab Emirates. ${ }^{5}$ King Saud University Hospital, Riyadh, Kingdom of Saudi Arabia. ${ }^{6}$ Ministry of Health, Muscat, Oman. ${ }^{7}$ Hamad Medical Corporation, Doha, Qatar. ${ }^{8}$ Al Amiri Hospital, Kuwait City, Kuwait. ${ }^{9}$ King Fahad National Guard Hospital, Riyadh, Kingdom of Saudi Arabia. ${ }^{10}$ Ministry of Health, Riyadh, Kingdom of Saudi Arabia. ${ }^{11}$ School of Medicine, Al-Imam Mohammad Ibn Saud Islamic University (IMSIU), Riyadh, Kingdom of Saudi Arabia. ${ }^{12}$ King Fahad General Hospital, Jeddah, Kingdom of Saudi Arabia. ${ }^{13}$ King Fahad Hospital of the University, Khobar, Kingdom of Saudi Arabia. ${ }^{14}$ Soliman Fakieh Hospital, Jeddah, Kingdom of Saudi Arabia. ${ }^{15}$ Dubai Hospital, Dubai, United Arab Emirates. ${ }^{16}$ American Hospital, Dubai, United Arab Emirates. ${ }^{17}$ Rashid Hospital, Dubai, United Arab Emirates. ${ }^{18}$ Bahrain Defense Force Hospital, Manama, Bahrain.

${ }^{19}$ Department of Biochemistry, Sultan Qaboos University Hospital, P.O. Box 38, Al-Khod, 123 Muscat, Oman. ${ }^{20}$ Department of Physiology, College of Medicine $\&$ Health Sciences, Sultan Qaboos University, Muscat, Oman. ${ }^{21}$ Lipid Clinic Heart Institute (InCor), University of Sao Paulo Medical School Hospital, Sao Paulo, Brazil.
} 


\section{Acknowledgements}

We thank the patients, physicians, nurses, and support staff who participated in the CEPHEUS project for their invaluable cooperation. Thanks also go to ClinArt MENA for organizing the survey.

\section{Declaration of funding}

The CEPHEUS project was sponsored by AstraZeneca. The sponsor had no involvement in the study conception or design; analysis, or interpretation of data; writing, review, or approval of the manuscript; or the decision to submit the manuscript for publication.

\section{Declaration of financial/other relationships}

The authors disclose that they have no significant relationships with or financial interests in any commercial companies related to this study or article.

Received: 18 November 2015 Accepted: 10 July 2016

Published online: 26 July 2016

\section{References}

1. Mabry RM, Reeves MM, Eakin EG, Owen N. Gender differences in prevalence of the metabolic syndrome in Gulf Cooperation Council Countries: a systematic review. Diabet Med. 2010;27:593-7.

2. AlSuwaidi J, Zubaid M, El-Menyar AA, et al. Prevalence of the metabolic syndrome in patients with acute coronary syndrome in six middle eastern countries. J Clin Hypertens. 2010;12:890-9.

3. Al-Rasadi K, Sulaiman K, Panduranga P, Al-Zakwani I. Prevalence, characteristics, and in-hospital outcomes of metabolic syndrome among acute coronary syndrome patients from Oman. Angiology. 2011;62:381-9.

4. Lakka HM, Laaksonen DE, Lakka TA, et al. The metabolic syndrome and total and cardiovascular disease mortality in middle aged men. JAMA. 2002;288:2709-16.

5. Grundy SM, Cleeman Jl, Daniels SR, et al. Diagnosis and management of the metabolic syndrome: an American Heart Association/National Heart, Lung, and Blood Institute Scientific Statement. Circulation. 2005;112:2735-52.

6. Ilanne-Parikka P, Eriksson JG, Lindstrom J, et al. Effect of lifestyle intervention on the occurrence of metabolic syndrome and its components in the Finnish diabetes prevention study. Diabetes Care. 2008;31:805-7.

7. Arafah $\mathrm{M}, \mathrm{Al}$-Hinai AT, Al Mahmeed WA, et al. Centralized pan-middle east survey on the undertreatment of hypercholesterolemia: results From the CEPHEUS study in Arabian Gulf countries. Angiology. 2014;65:919-26.

8. Jacobson TA, Ito MK, Maki KC, et al. National lipid association recommendations for patient-centered management of dyslipidemia: part 1. Executive summary. J Clin Lipidol. 2014:8:473-88.

9. Alberti KG, Eckel RH, Grundy SM, et al. Harmonizing the metabolic syndrome: a joint interim statement of the International Diabetes Federation Task Force on Epidemiology and Prevention; National Heart, Lung, and Blood Institute; American Heart Association; World Heart Federation; International Atherosclerosis Society; and International Association for the Study of Obesity. Circulation. 2009;120:1640-5

10. James PA, Oparil S, Carter BL, et al. 2014 evidence-based guideline for the management of high blood pressure in adults: report from panel members appointed to the Eighth Joint National Committee (JNC 8). JAMA. 2014;311:507-20.

11. Reaven GM. Role of insulin resistance in human disease (syndrome X): an expanded definition. Annu Rev Med. 1993:44:121-31.

12. Eckel RH, Grundy SM, Zimmet PZ. The metabolic syndrome. Lancet. 2005:365:1415-28.

13. Assmann $G$, Schulte $H$. Relation of high-density lipoprotein cholesterol and triglycerides to incidence of atherosclerotic coronary artery disease (the PROCAM experience). Am J Cardiol. 1992;70:733-7.

14. Austin MA. Plasma triglyceride as a risk factor for cardiovascular disease. Can J Cardiol. 1998;14(Suppl B):14B-7B.

15. Gordon DJ, Probstfield JL, Garrison RJ, et al. High-density lipoprotein cholesterol and cardiovascular disease: four prospective American studies. Circulation. 1989;79:8-15.

16. Mottillo S, Filion KB, Genest J, et al. The metabolic syndrome and cardiovascular risk. A systematic review and meta-analysis. J Am Coll Cardiol. 2010;56:1113-32.
17. Reaven GM. Insulin resistance and compensatory hyperinsulinemia: role in hypertension, dyslipidemia, and coronary heart disease. Am Heart J. 1991;121:1283-8.

18. Lamarche B, Tchernof AG, Moorjani S, et al. Small, dense low-density lipoprotein particles as a predictor of the risk of ischemic heart disease in men: prospective results from the Quebec cardiovascular study. Circulation. 1997:95:69-75.

19. Adeli K, Taghibiglou C, Van Iderstine SC, et al. Mechanisms of hepatic very low density lipoprotein overproduction in insulin resistance. Trends Cardiovasc Med. 2001;11:170-6.

20. Karpe F, Tornwall P, Olivecrona T, et al. Composition of human low density: effects of postprandial triglyceride-rich lipoproteins, lipoprotein lipase, hepatic lipase and cholesteryl ester transfer protein. Atherosclerosis. 1993;98:33-49.

21. Mudd JO, Borlaug BA, Johnston PV, et al. Beyond low-density lipoprotein cholesterol: defining the role of low-density lipoprotein heterogeneity in coronary artery disease. J Am Coll Cardiol. 2007;50:173541.

22. Tato F, Vega GL, Grundy SM. Determinants of plasma HDL-cholesterol in hypertriglyceridemic patients: role of cholesterol-ester-transfer protein and lecithin cholesteryl acyl transferase. Arterioscler Tromb Vasc Biol. 1997; 17:35.

23. Ginsberg HN. Diabetic dyslipidemia: basic mechanisms underlying the common hypertriglyceridemia and low HDL cholesterol levels. Diabetes. 1996:45(Suppl3):S27-30.

24. Festa A, D'Agostino R Jr, Howard G, et al. Chronic subclinical inflammation as part of the insulin resistance syndrome: the insulin resistance atherosclerosis study (IRAS). Circulation. 2000;102:42-7.

25. Barzilay Jl, Abraham L, Heckbert SR, et al. The relation of markers of inflammation to the development of glucose disorders in the elderly: the cardiovascular health study. Diabetes. 2001;50:2384-9.

26. Pradhan AD, Manson JE, Rifai N, et al. C-reactive protein, interleukin 6, and risk of developing type 2 diabetes mellitus. JAMA. 2001;286:327-34.

27. Ridker PM, Buring JE, Cook NR, Rifai N. Creactive protein, the metabolic syndrome, and risk of incident cardiovascular events: an 8-year follow-up of 14,719 initially healthy American women. Circulation. 2003;107:391397.

28. Grundy SM. Pre-diabetes, metabolic syndrome, and cardiovascular risk. J Am Coll Cardiol. 2012;59:63543.

29. Panel ED, Grundy SM. An international atherosclerosis society position paper: global recommendations for the management of dyslipidemia. J Clin Lipid. 2014:8:2960.

30. Reiner Z, Catapano AL, DeBacker G, et al. ESC/EAS guidelines for the management of dyslipidemias - The task force for the management of dyslipidemias of the European Society of Cardiology (ESC) and the European Atherosclerosis Society (EAS). Eur Heart J. 2011:32:1769e818.

31. American Diabetes Association. Standards of medical care in diabetes-2014. Diabetes Care. 2014;37(Suppl 1):S14-80.

32. Deedwania P, Barter P, Carmena R, et al. Reduction of low-density lipoprotein cholesterol in patients with coronary heart disease and metabolic syndrome: analysis of the treating to new targets study. Lancet. 2006;368:919e28

33. Pyorala K, Ballantyne CM, Gumbiner B, et al. Reduction of cardiovascular events by simavastatin in nondiabetic coronary heart disease patients with and without the metabolic syndrome: subgroup analysis of the Scandinavian Simvastatin Survival Study (4S). Diabetes Care. 2004:27:1735e40.

34. Downs JR, Clearfield M, Weis S, et al. For the Air Force/Texas Coronary Atherosclerosis Prevention Study-primary prevention of acute coronary events with lovastatin in men and women with average cholesterol levels: results of AFCAPS/TexCAPS. JAMA. 1998;279:1615-22.

35. Ridker PM; JUPITER Study Group. Rosuvastatin in the primary prevention of cardiovascular disease among patients with low levels of low-density lipoprotein cholesterol and elevated high-sensitivity C-reactive protein: rationale and design of the JUPITER trial. Circulation. 2003;108:2292-7.

36. Cannon CP, Blazing MA, Giugliano RP, et al. Ezetimibe added to statin therapy after acute coronary syndromes. N Engl J Med. 2015:372:2387-97.

37. Keene D, Price C, Shun-Shin MJ, Francis DP. Effect on cardiovascular risk of high density lipoprotein targeted drug treatments niacin, fibrates, and CETP inhibitors: meta-analysis of randomised controlled trials including 117,411 patients. BMJ. 2014:349:4379. 
38. Robins SJ, Bloomfield HE. Fibric acid derivatives in cardiovascular disease prevention: results from the large clinical trials. Curr Opin Lipidol. 2006;17:431-9.

39. Sacks FM, Carey VJ, Fruchart JC. Combination lipid therapy in type 2 diabetes. N Engl J Med. 2010;363:692-4.

40. Wang F, Ye P, Hu D, Min Y, Zhao S, Wang Y, et al. Lipid-lowering therapy and lipid goal attainment in patients with metabolic syndrome in China: a subgroup analysis of the Dyslipidemia International Study-China (DYSIS-China). Atherosclerosis. 2014;237:99e105.
41. Chen CY, Chuang SY, Fang CC, et al. Gender disparities in optimal lipid control among patients with coronary artery disease. J Atheroscler Thromb. 2014;21:20-8.

42. Faharani P. Gender gap in lipid management amongst diabetes population: an observation. J Popul Ther Clin Pharmacol. 2014;21:181-4.

43. Magee MF, Tamis-Holland JE, Lu J, et al. Sex, prescribing practices and guideline recommended, blood pressure, and LDL cholesterol targets at baseline in the BARI 2D trial. Int J Endocrinol. 2015;2015:610239.

\section{Submit your next manuscript to BioMed Central and we will help you at every step:}

- We accept pre-submission inquiries

- Our selector tool helps you to find the most relevant journal

- We provide round the clock customer support

- Convenient online submission

- Thorough peer review

- Inclusion in PubMed and all major indexing services

- Maximum visibility for your research

Submit your manuscript at

www.biomedcentral.com/submit 